\title{
Immunosuppressive Drugs and Kidney Post-transplant Diabetes Mellitus
}

\author{
Ismael Bilal Ismael', Sarhang Hasan Azeez ${ }^{2 *}$ \\ ${ }^{1}$ College of Nursing, Hawler Medical University, Erbil, Iraq \\ ${ }^{2}$ Biology Department, College of Education, Salahaddin University-Erbil, Erbil, Iraq \\ *Corresponding Author: Sarhang Hasan Azeez, College of Education, Salahaddin University-Erbil, Erbil, Iraq. \\ Tel: +964-750-4624662, Email: Sarhang.azeez@su.edu.krd
}

Received January 30, 2019; Accepted May 26, 2019; Online Published June 15, 2019

\begin{abstract}
Background: As the rate of renal transplantation increases, more immunosuppressive drugs such as cyclosporine $\mathrm{A}$ (CsA) are consumed, particularly during the early months following transplantation, leading to post-transplant diabetes mellitus (PTDM) which can cause death.

Objective: The present study examined the role of CsA in causing PTDM and other effective factors among patients with chronic kidney disease (CKD) who had undergone renal replacement therapy.

Methods: The present investigation was a quantitative case-control study carried out on 30 CKD patients who had undergone renal transplantation and 30 healthy individuals. A questionnaire was utilized to gather their demographic information, and direct interviews were conducted with the subjects. To examine random blood sugar (RBS), white blood cell (WBC) count, creatinine level, and blood urea nitrogen (BUN), blood samples were obtained from the subjects. The mentioned parameters were analyzed using SPSS 22.0.

Results: According to the results, the groups were homogenous in age, body mass index (BMI), and male-to-female ratio. However, there were significant differences between the two groups in RBS $(P=0.011)$, WBC count $(P=0.031)$, creatinine level $(P=0.001)$, and BUN $(P=0.001)$.

Conclusion: Failure of allograft survival of renal transplantation was found to be a leading cause of death, which has been reportedly been treated by the consumption of immunosuppressive drugs such as CsA. However, this drug can increase the patient's chances of developing PTDM. PTDM development can be reduced by applying a dosage of $10 \mathrm{mg} / \mathrm{kg} / \mathrm{d}$ during the first week and 8-9 mg/kg/day during weeks 2-5 following transplantation.

Keywords: Immunosuppressive Agents, Cyclosporine A (CsA), Chronic kidney Disease, Renal Transplantation, Diabetes Mellitus
\end{abstract}

\section{Background}

Decreased uremic toxin and improved glucose tolerance have been reported as the results of successful renal transplantation. However, the consumption of immunosuppressive drugs following renal transplantation can, to a large extent, lead to glucose intolerance, finally resulting in the development of post-transplant diabetes mellitus (PTDM). ${ }^{1-3}$ Different research studies have reported that patients who have undergone renal transplantation are likely to experience PTDM during the first 3 months after transplantation and that there will be an increase in the risk of transplantation failure, ${ }^{4,5}$ mortality, ${ }^{6-8}$ and infectious and cardiovascular diseases ${ }^{9,10}$ as a result of PTDM.

It has also been demonstrated that PTDM developed in $40 \%$ of patients as a result of employing high-dose corticosteroid therapy in the early period after renal transplantation. ${ }^{7}$ However, once better immunosuppressive drugs like tacrolimus and cyclosporine A (CsA) were introduced, a significant decrease in corticosteroid consumption was observed, which then led to significant improvements in transplantation survival. ${ }^{11}$ Although PTDM incidence has remarkably decreased as a result of introducing and employing immunosuppressive drugs to enhance allograft survival renal transplantation, PTDM has been reported to be experienced by $20 \%$ of transplant patients; therefore, the diabetogenic feature of these drugs have been pinpointed. ${ }^{12}$

Asindicated by experimental studies, immunosuppressive drugs like CsA and tacrolimus can lead to diabetes by decreasing insulin production and release, reducing peripheral insulin sensitivity, and being $\beta$-cell toxic. ${ }^{13}$ These 2 immunosuppressive drugs have also been the focus in various comparative studies which have revealed

Copyright $\odot 2019$ The Author(s). This is an open-access article distributed under the terms of the Creative Commons Attribution License (http:// creativecommons.org/licenses/by/4.0), which permits unrestricted use, distribution, and reproduction in any medium, provided the original work is properly cited. 
a significantly higher incidence of PTDM as a result of tacrolimus therapy compared to CsA therapy. ${ }^{14,15}$ Other risk factors including a history of diabetes in the family, obesity, human leukocyte antigen type, race, and age have also been reported to be involved with the incidence of PTDM. ${ }^{16,17}$ It should be noted that because PTDM has not uniformly been defined, classifying patients with varying degrees of glucose tolerance is difficult, which, in turn, complicates evaluating the importance of different risk factors affecting long-term outcomes. ${ }^{18}$

As suggested by research studies, different protocols of immunosuppressive drugs need to be employed for different patients. For example, patients with delayed graft function, a higher level of preformed antibodies, and previous transplants, or young patients should be given higher doses of immunosuppression. In addition, patients receiving kidneys from older donors are likely to be less tolerant to immunological assault and other aggression, while those with kidneys received from well-matched donors may need fewer immunosuppressive drugs. ${ }^{19}$ It has also been shown that acute rejection may happen during the first months after transplantation (induction phase) and decline later on (maintenance phase). As a result, the highest level of immunosuppressive drugs should be administered during the early period followed by decreased levels for long-term therapy. ${ }^{20}$

Although controlling immunologic phenomena after transplantation and allograft survival have improved greatly, ${ }^{21}$ mortality among transplant recipients has been frequently referred to as a threat to the success of renal transplantation. ${ }^{22,23}$ Cardiovascular causes are responsible for a high mortality rate among renal transplant recipients ${ }^{24}$; therefore, identifying the variables relevant to cardiovascular risks is highly significant. According to research, there is a relationship between post-transplant insulin resistance in patients consuming immunosuppressive drugs (such as CsA and tacrolimus) and cardiovascular risk..$^{25,26}$

\section{Objective}

Since renal transplantation is quite prevalent, and the high mortality rate caused by transplant failure has been reported to be correlated with cardiovascular risks associated with the consumption of immunosuppressive drugs, the current study examined the role CsA plays in causing PTDM among patients with chronic kidney disease (CKD) who have undergone renal replacement therapy. Other aims of the present study were to determine the different factors involved with PTDM, estimate the proper dose of CsA to prevent PTDM incidence, and determine the side effects of the drug.

\section{Methods}

\subsection{Study Design and Setting}

Using a quantitative method and following a casecontrol design, the present study was conducted in Zheen International hospital located in Erbil, the Kurdistan region of Iraq, over a 6-month period from October 2016 to March 2017.

\subsection{Participants and Intervention}

The study sample in the present case-control study consisted of 30 patients with renal transplantation and 30 healthy individuals without renal transplantation who had referred to Zheen International hospital located in Erbil, the Kurdistan region of Iraq. CKD patients, $\geq 18$ years of age, who had undergone renal transplantation were included in the study. Patients with significant coronary artery disease (CAD), who were awaiting a repeat transplant, or had an unwillingness to participate in the study were excluded. A convenience purposive sampling method was utilized to select the subjects. who were then assigned into a patient group (case) and a healthy group (control). There were 30 individuals in each group who were homogenous in terms of their body mass index (BMI) $\left(25.33 \pm 2.2 \mathrm{~kg} / \mathrm{m}^{2}\right.$ in the case group and $24.88 \pm 1.35 \mathrm{~kg} / \mathrm{m}^{2}$ in the control group) and mean age $(33.8 \pm 3.9$ and $35.3 \pm 2.2$, respectively, in case and control groups). CsA at doses of $10 \mathrm{mg} / \mathrm{kg} / \mathrm{d}$ for 1-6 days following transplantation and $8-9 \mathrm{mg} / \mathrm{kg} / \mathrm{d}$ for 2-5 weeks following transplantation was administered to the patients during the maintenance phase, while the control group was not given anything. To complete the questionnaire consisting of questions regarding the subjects' family history of diabetes, gender, and age, each individual was interviewed face to face. For the purpose of biochemical examinations, blood samples $(5 \mathrm{~mL})$ were taken from the individuals of both groups.

\subsection{Data Collection and Instruments}

A self-designed questionnaire was used to gather the participants' demographic data which included gender, age, and history of smoking, pre- and post-transplant diabetes, and family history of diabetes under the supervision of specialists in the fields. The questionnaire was valid (overall alpha value of 0.89 ) and reliable $(r=0.85$, ranging from $0.79-0.90$ ). Before and 4 to 6 weeks following renal transplantation, the case group's data was collected through face-to-face interviews with the subjects. Blood samples were also obtained on which biochemical examinations were conducted so as to collect the required data on the subjects' random blood sugar (RBS), white blood cell count (WBC), creatinine level, and blood urea nitrogen (BUN).

\subsection{Data Analysis}

Quantitative data was given as mean \pm standard deviation (SD). The independent sample $t$ test was employed to compare the parameter means (age, BMI, BUN, creatinine, WBC, RBC, cholesterol, triglyceride, $\mathrm{K}^{+}, \mathrm{Na}^{+}$, and $\mathrm{Ca}^{+}$) between the two studied groups (case and control). A $P$ value of $<0.05$ was considered as the statistically significant level. SPSS 22.0 was used to analyze the data.

\section{Results}

Analysis of the data collected from the questionnaire 
demonstrated that the case and control subjects' mean age was $33.8 \pm 3.9$ and $35.3 \pm 2.2$ years, respectively. The results also indicated that $55.6 \%$ of the case subjects $(n=17)$ were males and $44.4 \%(n=13)$ were females. In the control group, half of the subjects (50\%) were women and half (50\%) were men. In addition, it was observed that the case group had an average BMI of $25.33 \pm 2.2$, and the control group's average BMI was $24.88 \pm 1.35$. It was concluded that the two groups were not significantly different in terms of the above-mentioned variables (Table 1).

Data analysis also revealed that $20.4 \%$ of the case patients $(\mathrm{n}=8)$ smoked, while none of the control subjects smoked. It was also observed that $9(24.1 \%)$ case patients had a family history of diabetes, 7 (16.7\%) had hypertension, $8(26 \%)$ had post-transplant diabetes, 4 (11\%) had pretransplant diabetes, and 10 patients (13\%) had diabetes, while none of the control subjects had these variables. Thus, the difference between the two groups in terms of these variables was significant (Table 1).

The data related to the CsA dosage that was administered during the maintenance phase is presented in Table 2. As indicated, the patients in the case group were given $10 \mathrm{mg} / \mathrm{kg} / \mathrm{d}$ for a period of 1 to 6 days following renal transplantation and $8-9 \mathrm{mg} / \mathrm{kg} / \mathrm{d}$ for a period of $2-5$ weeks after renal transplantation (Table 2).

Based on the results of ANOVA indicated in Table 3, it was concluded that there was a significant difference between the two groups in terms of their BUN $(P=0.001)$, creatinine level $(P=0.001)$, WBC counts $(P=0.031)$, and RBS $(P=0.011)$.

According to the results of the present study, the 2 groups were significantly different in terms of their blood and serum parameters. A significant increase was observed in cholesterol and triglyceride levels, and serum ions (particularly potassium ions) underwent a drastic rise; the difference was significant. Moreover, the same condition

Table 1. Characteristics of Subjects in the Case and Control Groups

\begin{tabular}{|c|c|c|c|c|}
\hline \multirow{2}{*}{\multicolumn{2}{|c|}{ Characteristics }} & \multicolumn{2}{|c|}{ Groups } & \multirow[b]{2}{*}{$P$ Value } \\
\hline & & $\begin{array}{l}\text { Case } \\
\mathrm{n}=30\end{array}$ & $\begin{array}{c}\text { Control } \\
n=30\end{array}$ & \\
\hline \multicolumn{2}{|c|}{ Age (mean \pm SD) } & $33.8 \pm 3.9$ & $35.3 \pm 2.2$ & 0.690 \\
\hline \multirow{2}{*}{ Gender } & Male & $17 / 30(55.6 \%)$ & $15 / 30(50 \%)$ & 0.901 \\
\hline & Female & $13 / 30(44.4 \%)$ & $15 / 30(50 \%)$ & 0.824 \\
\hline \multicolumn{2}{|c|}{$\mathrm{BMI}($ Mean $\pm \mathrm{SD})$} & $25.33 \pm 2.2$ & $24.88 \pm 1.35$ & 0.726 \\
\hline \multicolumn{2}{|c|}{ Smokers } & $8 / 30(20.4 \%)$ & - & - \\
\hline \multicolumn{2}{|c|}{ Diabetes } & 10/30 (13\%) & - & - \\
\hline \multicolumn{2}{|c|}{ Pre-transplantation } & $4 / 30(11 \%)$ & - & - \\
\hline \multicolumn{2}{|c|}{ Post-transplantation } & $8 / 30(26 \%)$ & - & - \\
\hline \multicolumn{2}{|c|}{ Hypertension } & $7 / 30(16.7 \%)$ & - & - \\
\hline \multicolumn{2}{|c|}{ Family history } & $9 / 30(24.1 \%)$ & - & - \\
\hline
\end{tabular}

Table 2. Cyclosporine A (CsA) Dosage Given to Patients With Renal Transplantation

\begin{tabular}{lll}
\hline Immunosuppressive Drug & Maintenance Phase & Period \\
\hline CsA dosage & $10 \mathrm{mg} / \mathrm{kg} /$ day & $1-6$ days \\
CsA dosage & $8-9 \mathrm{mg} / \mathrm{kg} /$ day & $2-5$ weeks \\
\hline
\end{tabular}

was observed for calcium, while changes in the sodium ion was not significant (Table 4).

\section{Discussion}

Based on the results of the present study, it was concluded that the patients and the healthy individuals were not significantly different in terms of their BMI. However, research has indicated a higher risk of developing new onset diabetes mellitus after transplant (NODAT) among patients who have a BMI of equal to or greater than $30 \mathrm{~kg} /$ $\mathrm{m}^{2},{ }^{27,28}$ which cannot be compared with the current results, because none of the subjects had a BMI of equal to or greater than $30 \mathrm{~kg} / \mathrm{m}^{2}$.

Diabetes mellitus has been cited as one of the most frequent causes of CKD. Moreover, about 30\% of nondiabetic patients with renal transplantation experience NODAT, also referred to as PTDM. ${ }^{29}$ This finding is in line with that of the current study, where diabetes mellitus (DM) developed after renal transplantation in 8 out of 30 patients $(26 \%)$ (Table 1 ). Depending on the type of transplantation, i.e. renal, liver, or heart transplantation, the definition of NODAT, and the study design, a range of $4 \%$ to $40 \%$ of NODAT development has been reported by other studies..$^{30,31}$

According to the results of the present study, a family history of diabetes mellitus, hypertension, and smoking with frequencies of $24.1 \%, 16.7 \%$, and $20.4 \%$, respectively, were among other effective risk factors in the development of PTDM. This finding is in agreement with those of the studies carried out by Rodrigo et al and Kaposztas et al. ${ }^{27,32}$ Rodrigo et alalso reported age as one of the effective factors in NODAT ${ }^{27}$; however, age was not found to be an effective factor in NODAT in the present study. This difference can be related to the fact that both groups in the present study

Table 3. BUN Urea, Creatinine, and WBC Counts of the Case and Control Groups

\begin{tabular}{lccl}
\hline \multirow{2}{*}{ Parameters } & \multicolumn{2}{c}{ Group } & \\
\cline { 2 - 3 } & $\begin{array}{c}\text { Case } \\
\text { Mean } \pm \text { SD }\end{array}$ & $\begin{array}{c}\text { Control } \\
\text { Mean } \pm \text { SD }\end{array}$ & \\
\hline BUN $(\mathrm{mg} / \mathrm{dL})$ & $132.11 \pm 12.53$ & $45.13 \pm 3.87$ & 0.001 \\
Creatinine $(\mathrm{mg} / \mathrm{dL})$ & $6.14 \pm 0.88$ & $1.04 \pm 0.09$ & 0.001 \\
WBC $\left(10^{3} / \mathrm{mL}\right)$ & $6.33 \pm 1.21$ & $7.56 \pm 0.19$ & 0.031 \\
RBS $(\mathrm{mg} / \mathrm{dL})$ & $128.8 \pm 6.560$ & $95.36 \pm 2.260$ & 0.011 \\
\hline
\end{tabular}

* The independent sample $t$ test was used to analyze the mean differences of parameters between case and control groups.

Table 4. Comparison of Patients and Control Group Regarding Blood Glucose, Cholesterol, Triglyceride, and Serum Ion Levels

\begin{tabular}{lccc}
\hline Parameters & RT $($ Mean \pm SD) & Control $($ Mean \pm SD) & $P$ Value \\
\hline Cholesterol & $200.8 \pm 12.093$ & $171.1 \pm 9.111$ & 0.025 \\
Triglycerides & $174.4 \pm 12.45$ & $102.3 \pm 6.436$ & 0.001 \\
$\mathrm{~K}^{+}$ & $8.981 \pm 0.2130$ & $4.832 \pm 0.1791$ & 0.021 \\
$\mathrm{Ca}^{+}$ & $6.813 \pm 0.4193$ & $1.180 \pm 0.0264$ & 0.001 \\
$\mathrm{Na}^{+}$ & $132.2 \pm 1.484$ & $136.1 \pm 1.797$ & 0.117 \\
\hline
\end{tabular}

* The independent sample $t$ test was used to analyze the mean differences of parameters between case and control groups 
were homogenous in terms of age. It has also been reported that patients with previous type- 2 diabetes are more prone to develop PTDM, ${ }^{28}$ which is also supported by the results of the present study (Table 1 ).

According to the research, immunosuppressive drugs like cyclosporine and tacrolimus can help with PTDM prevention and prolonged graft survival. ${ }^{33,34}$ There is research-based evidence showing that the transplanted organ might be rejected during the first months following transplantation (induction phase) and decrease later on (maintenance phase). As a result, patients need to be given immunosuppressive drugs at the highest level during the early period, and the dose should be reduced for long-term therapy. ${ }^{20}$ Accordingly, the patients in the present study were given $10 \mathrm{mg} / \mathrm{kg}$ of CsA per day during the first 6 days following the transplantation, and $8-9 \mathrm{mg} / \mathrm{kg} / \mathrm{d}$ during the subsequent 2-5 weeks.

Moreover, a significant difference was found between the two groups regarding their BUN; therefore, BUN was found to be a PTDM risk factor; however, the development of diabetes mellitus following transplantation, as indicated by research, cannot be predicted through BUN. ${ }^{35}$

In the present study, the case group patients with renal transplantation and a history of PTDM had a significantly higher level of serum creatinine; therefore, creatinine level was regarded as a risk factor for PTDM. Contradictory results have been reported with regard to the effect of serum creatinine level on PTDM development. For example, Sumrani et al reported that creatinine level does not influence the rate of PTD, ${ }^{9}$ while Choi and Kwon demonstrated that PTDM incidence can be predicted through creatinine level. ${ }^{36}$ This contradiction in research findings can be attributed to discrepancy in different study samples, durations of the studies, and the tests employed.

The results of the present study revealed that there was a slightly significant difference between the two groups regarding their WBC count $(P<0.05)$, which gave way to this conclusion that PTDM incidence cannot be well predicted through WBC. According to research, WBC has been reported as an effective factor in prediction of graft survival following orthotopic liver transplantation. ${ }^{37}$

According to the results of the present study, RBS (or random glucose) is an effective factor in the development of PTDM. This finding is in agreement with reports of the American Diabetes Association (ADA) and the World Health Organization (WHO) that referred to a random glucose level of $200 \mathrm{mg} / \mathrm{dL}(11.1 \mathrm{mmol} / \mathrm{L})$ as one of the predictive factors for PTDM. ${ }^{38.39}$

Patients with renal disease have frequently been reported to have dyslipidemia. ${ }^{40-42}$ A large number of patients with renal disease have been reported to undergo atherogenic changes in the composition and level of lipoproteins, which are referred to as risk factors for cardiovascular diseases (CVD) in the general population. ${ }^{43-45}$ Given the patient population and the time point of examining the serum lipids following transplantation, a range of $16 \%-72 \%$ has been reported for dyslipidemia prevalence in patients with renal transplantation. ${ }^{46}$

Although there is no clear understanding of the pathogenesis of lipid pattern changes in patients with renal transplant, it seems to be multifactorial. Among these, immunosuppressive therapy and concomitant steroid are probably the most significant. ${ }^{47}$ The present study investigated the lipid profiles of patients with renal transplantation in order to specify the nature of lipid abnormalities and also performed a critical analysis on the collected data to interpret their utility for therapeutic interventions.

Depending on the time the post-transplantation serum lipid levels were obtained, $16 \%-78 \%$ of recipients might develop post-transplant hyperlipidemia. ${ }^{48}$ Most patients (82\%) develop hypercholesterolemia within 6 months following transplantation, while the highest incidence rate of hypertriglyceridemia has been reported to be 12 months after transplantation. ${ }^{49}$

There is a poor understanding of the hyperlipidemia pathogenesis in renal transplant recipients; however, it seems to be multifactorial. Age, gender, body weight, renal dysfunction, pre-transplant lipid level, concomitant use of diuretics or beta blockers, proteinuria, steroid use, diabetes mellitus, and cyclosporine use have been pinpointed as factors associated with post-transplant hyperlipidemia. ${ }^{47,49}$ However, it is not clear how these factors contribute to the incidence of hyperlipidemia after transplantation.

It has been reported that early after transplantation, there is a relationship between hyperlipidemia and immunosuppressive therapy; however, persistent hyperlipidemia in the late post-transplantation period can be caused by factors other than immunosuppressive therapy. ${ }^{47}$ Post-transplantation morbidity and mortality among long-term renal transplant survivors have been attributed to CVD. ${ }^{48,50}$ Patients who develop CAD after renal transplantation have been reported to be older males, have diabetes with higher cholesterol levels, smoke more, and experience more episodes of acute renal allograft rejection, and thus have received a greater cumulative dose of steroids. ${ }^{51}$ According to several clinical studies, there is a correlation between chronic allograft rejection and hyperlipidemia. ${ }^{47}$ The most consistent predictor of chronic allograft failure has been reported to be increased serum TG levels. However, this relationship between hyperlipidemia and chronic allograft failure can be caused by reasons other than the cause of renal allograft failure ${ }^{47}$ Hyperlipidemia should be assessed immediately after transplantation and followed by the measurement of serum lipid concentrations as soon as indicated or once a year. Certain therapeutic implications can be concluded from the inverse correlation between duration of transplant and lipid abnormalities. For example, the lipid profile varies during the first 8-12 months following transplantation. Therefore, it should not be considered as therapy basis. Hyperlipidemia treatment decision needs to be according to the lipid levels and the existence of positive risk factors for CAD such as age $>55$ years in females, age $>45$ years in males, current cigarette 
smoking, family history of premature CAD, HDL-C $<35$ $\mathrm{mg} / \mathrm{dL}$, diabetes mellitus, and blood pressure $>140 / 90 \mathrm{~mm}$ $\mathrm{Hg}$ in spite of antihypertensive therapy. ${ }^{52}$

In patients with renal transplantation, hyperkalemia is often observed in association with renal tubular acidosis. It can also be seen without the presence of any of the factors mentioned above. The translocation of potassium and glucose from the extracellular to the intracellular compartment can be reduced by insulinopenia or insulin resistance. It can also lead to hyperglycemia and hyperkalemia in the post-transplant setting, particularly in insulin-dependent diabetic patients. ${ }^{53}$ The time course of hyperkalemia following renal transplantation has been described in a small number of studies. In a study conducted on type-1 diabetic patients in 1996, on average, renal transplantation patients developed hyperkalemia up to day of 100 after the transplantation, and only 2 patients developed hyperkalemia 8 months following transplantation. ${ }^{54}$ Hyperkalemia has been reported to be more frequent in patients on tacrolimus compared to those on cyclosporine. $^{55}$

\section{Conclusion}

The results of the current study revealed that hypertension, pre-transplantation diabetes, BUNn, family history of diabetes, RBS, and serum creatinine level can influence and predict the development of PTDM. Moreover, mortality among transplant patients can be due to graft survival failure; therefore, its early diagnosis and prevention are recommended. Although the administration of immunosuppressive drugs (CsA) has been reported to increase graft survival chances among transplant recipients, administering this drug in wrong doses can lead to an increase in incidence of PTDM. According to the results of the current study, CsA administration should begin from $10 \mathrm{mg} / \mathrm{kg} / \mathrm{d}$ in the first week and decrease to $8-9 \mathrm{mg} / \mathrm{kg} / \mathrm{d}$ during weeks 2-5 after transplantation.

\section{Limitations of the present study}

As a limitation of the present study, intragroup analysis was not conducted in the case group so as to achieve a deeper understanding of PTDM causes. The short duration of the experiment was another limitation of the study. More prolonged studies are recommended, in which groups of PTDM patients with individual and biological differences should be compared.

\section{Authors' Contributions}

Both authors contributed equally to this study.

\section{Conflict of Interest Disclosures}

The authors declare that they have no conflicts of interest.

\section{Ethical Approval}

The necessary ethical approval was obtained from the Ethics Committee of the College of Nursing, Hawler Medical University. Moreover, the required permission

\section{Research Highlights}

\section{What Is Already Known?}

Renal transplantation failure is associated with the consumption of immunosuppressive drugs such as cyclosporine. Consumption will lead to post-transplant diabetes mellitus particularly during the early months following transplantation which can cause death.

\section{What This Study Adds?}

The incorrect administration of immunosuppressive drugs, including CsA, can lead to an increase in the development of post-transplant diabetes mellitus among patients with CKD who have undergone renal replacement therapy. PTDM development can be reduced by applying a dosage of $10 \mathrm{mg} / \mathrm{kg} / \mathrm{d}$ during the first week and $8-9 \mathrm{mg} /$ $\mathrm{kg} / \mathrm{d}$ during weeks 2-5 following transplantation.

was obtained from the President of Zheen International Hospital in Erbil, the Kurdistan Region of Iraq. In addition, a thorough explanation of the method and objectives of the study was provided to the subjects, and they were ensured that their information would be kept confidential and that they could withdraw from the study whenever they wished. Finally, the subjects signed an informed consent form.

\section{References}

1. Sarno G, Muscogiuri G, De Rosa P. New-onset diabetes after kidney transplantation: prevalence, risk factors, and management. Transplantation. 2012;93(12):1189-1195. doi:10.1097/TP.0b013e31824db97d.

2. Chadban S. New-onset diabetes after transplantation--should it be a factor in choosing an immunosuppressant regimen for kidney transplant recipients. Nephrol Dial Transplant. 2008;23(6):1816-1818. doi:10.1093/ndt/gfn052.

3. Vincenti F, Friman S, Scheuermann E, et al. Results of an international, randomized trial comparing glucose metabolism disorders and outcome with cyclosporine versus tacrolimus. Am J Transplant. 2007;7(6):1506-1514. doi:10.1111/j.16006143.2007.01749.x

4. Roth D, Milgrom M, Esquenazi V, Fuller L, Burke G, Miller J. Posttransplant hyperglycemia. Increased incidence in cyclosporine-treated renal allograft recipients. Transplantation. 1989;47(2):278-281. doi:10.1097/00007890-19890200000016.

5. Vesco L, Busson M, Bedrossian J, Bitker MO, Hiesse C, Lang P. Diabetes mellitus after renal transplantation: characteristics, outcome, and risk factors. Transplantation. 1996;61(10):14751478. doi:10.1097/00007890-199605270-00011.

6. Lindholm A, Albrechtsen D, Frodin L, Tufveson G, Persson $\mathrm{NH}$, Lundgren G. Ischemic heart disease--major cause of death and graft loss after renal transplantation in Scandinavia. Transplantation. 1995;60(5):451-457. doi:10.1097/00007890199509000-00008

7. Friedman EA, Shyh TP, Beyer MM, Manis T, Butt KM Posttransplant diabetes in kidney transplant recipients. Am Nephrol. 1985;5(3):196-202. doi:10.1159/000166932.

8. Kasiske BL, Snyder JJ, Gilbertson D, Matas AJ. Diabetes mellitus after kidney transplantation in the United States. Am J Transplant. 2003;3(2):178-185. doi:10.1034/j.16006143.2003.00010.x. 
9. Sumrani NB, Delaney V, Ding ZK, et al. Diabetes mellitus after renal transplantation in the cyclosporine era--an analysis of risk factors. Transplantation. 1991;51(2):343-347. doi:10.1097/00007890-199102000-00014.

10. Boudreaux JP, McHugh L, Canafax DM, et al. The impact of cyclosporine and combination immunosuppression on the incidence of posttransplant diabetes in renal allograft recipients. Transplantation. 1987;44(3):376-381. doi:10.1097/00007890198709000-00010.

11. Sampaio EL, Pinheiro-Machado PG, Garcia R, et al. Mycophenolate mofetil vs. sirolimus in kidney transplant recipients receiving tacrolimus-based immunosuppressive regimen. Clin Transplant. 2008;22(2):141-149. doi:10.1111/ j.1399-0012.2007.00756.x.

12. Weir MR, Fink JC. Risk for posttransplant Diabetes mellitus with current immunosuppressive medications. Am J Kidney Dis. 1999;34(1):1-13. doi:10.1016/S0272-6386(99)70101-0.

13. Drachenberg CB, Klassen DK, Weir MR, et al. Islet cell damage associated with tacrolimus and cyclosporine: morphological features in pancreas allograft biopsies and clinical correlation. Transplantation. 1999;68(3):396-402. doi:10.1097/00007890199908150-00012.

14. Pirsch JD, Miller J, Deierhoi MH, Vincenti F, Filo RS. A comparison of tacrolimus (FK506) and cyclosporine for immunosuppression after cadaveric renal transplantation. FK506 Kidney Transplant Study Group. Transplantation. 1997;63(7):977-983. doi:10.1097/00007890-19970415000013.

15. Mayer AD, Dmitrewski J, Squifflet JP, et al. Multicenter randomized trial comparing tacrolimus (FK506) and cyclosporine in the prevention of renal allograft rejection: a report of the European Tacrolimus Multicenter Renal Study Group. Transplantation. 1997;64(3):436-443. doi:10.1097/00007890-199708150-00012.

16. Silva F, Queiros J, Vargas G, Henriques A, Sarmento A, Guimaraes S. Risk factors for posttransplant diabetes mellitus and impact of this complication after renal transplantation. Transplant Proc. 2000;32(8):2609-2610. doi:10.1016/S00411345(00)01805-4.

17. Hathaway DK, Tolley EA, Blakely ML, Winsett RP, Gaber AO. Development of an index to predict posttransplant diabetes mellitus. Clin Transplant. 1993;7(4):330-338.

18. Jindal RM. Posttransplant diabetes mellitus--a review. Transplantation. 994;58(12):1289-1298.

19. Danovitch GM. Immunosuppressive medications for renal transplantation: a multiple choice question. Kidney Int. 2001;59(1):388-402. doi:10.1046/j.1523-1755.2001.00501.x.

20. Muntean A, Lucan M. Immunosuppression in kidney transplantation. Clujul Med. 2013;86(3):177-180.

21. Hariharan S, Johnson CP, Bresnahan BA, Taranto SE, McIntosh MJ, Stablein D. Improved graft survival after renal transplantation in the United States, 1988 to 1996. N Engl J Med. 2000;342(9):605-612. doi:10.1056/nejm200003023420901.

22. Ojo AO, Hanson JA, Wolfe RA, Leichtman AB, Agodoa LY, Port FK. Long-term survival in renal transplant recipients with graft function. Kidney Int. 2000;57(1):307-313. doi:10.1046/j.15231755.2000.00816.x.

23. Cosio FG, Alamir A, Yim S, et al. Patient survival after renal transplantation: I. The impact of dialysis pre-transplant. Kidney Int. 1998;53(3):767-772. doi:10.1046/j.15231755.1998.00787.x.

24. USRDS: United States Renal Data System 1996 annual data report. Am J Kidney Dis. 1996;28:S1-S152.

25. Cosio FG, Kudva $Y$, van der Velde $M$, et al. New onset hyperglycemia and diabetes are associated with increased cardiovascular risk after kidney transplantation. Kidney Int. 2005;67(6):2415-2421. doi:10.1111/j.1523- 1755.2005.00349.x.

26. Liefeldt L, Budde K. Risk factors for cardiovascular disease in renal transplant recipients and strategies to minimize risk. Transpl Int. 2010;23(12):1191-1204. doi:10.1111/j.14322277.2010.01159.x.

27. Rodrigo E, Fernandez-Fresnedo G, Valero R, et al. Newonset diabetes after kidney transplantation: risk factors. J Am Soc Nephrol. 2006;17(12 Suppl 3):S291-295. doi:10.1681/ ASN.2006080929.

28. Gourishankar S, Jhangri GS, Tonelli $M$, Wales LH, Cockfield SM. Development of diabetes mellitus following kidney transplantation: a Canadian experience. Am J Transplant. 2004:4(11):1876-1882. doi:10.1111/j.16006143.2004.00591.x

29. Peev V, Reiser J, Alachkar N. Diabetes mellitus in the transplanted kidney. Front Endocrinol (Lausanne). 2014;5:141. doi:10.3389/fendo.2014.00141.

30. Kasiske BL, Snyder IJ, Gilbertson D, Matas AJ. Diabetes mellitus after kidney transplantation in the United States. Am J Transplant. 2003;3(2):178-185. doi:10.1034/j.16006143.2003.00010.x.

31. Davidson J, Wilkinson A, Dantal J, et al. New-onset diabetes after transplantation: 2003 International consensus guidelines. Proceedings of an international expert panel meeting. Barcelona, Spain, 19 February 2003. Transplantation. 2003;75(10 Suppl):Ss3-24. doi:10.1097/01.tp.0000069952.49242.3e.

32. Kaposztas Z, Gyurus E, Kahan BD. New-onset diabetes after renal transplantation: diagnosis, incidence, risk factors, impact on outcomes, and novel implications. Transplant Proc. 2011;43(5):1375-1394. doi:10.1016/j. transproceed.2011.04.008.

33. Cosio FG, Hickson LJ, Griffin MD, Stegall MD, Kudva Y. Patient survival and cardiovascular risk after kidney transplantation: the challenge of diabetes. Am J Transplant. 2008;8(3):593-599. doi:10.1111/j.1600-6143.2007.02101.x.

34. Shivaswamy V, Boerner B, Larsen J. Post-transplant diabetes mellitus: causes, treatment, and impact on outcomes. Endocr Rev. 2016;37(1):37-61. doi:10.1210/er.2015-1084.

35. Seifi S, Rahbar M, Lessan-Pezeshki M, et al. Posttransplant diabetes mellitus: incidence and risk factors. Transplant Proc. 2009;41(7):2811-2813. doi:10.1016/j. transproceed.2009.07.043.

36. Choi JY, Kwon OJ. Post-transplant diabetes mellitus: is it associated with poor allograft outcomes in renal transplants? Transplant Proc. 2013;45(8):2892-2898. doi:10.1016/j. transproceed.2013.08.067

37. Helfritz FA, Lehner F, Manns MP, Ciesek S, Klempnauer J. Perioperative white blood cell count as a marker for patient and graft survival after orthotopic liver transplantation. J Hepatol Gastroint Dis. 2015;1(1):1-5.

38. American Diabetes Association. (2) Classification and diagnosis of diabetes. Diabetes Care. 2015;38 Suppl:S8-s16. doi:10.2337/dc15-S005.

39. World Health Organization (WHO). Definition and diagnosis of diabetes mellitus and intermediate hyperglycaemia. Report of a WHO/IDF Consultation. Geneva, Switzerland: WHO; 2006.

40. Keane WF, Kasiske BL. Hyperlipidemia in the nephrotic syndrome. N Engl J Med. 1990;323(9):603-604. doi:10.1056/ nejm199008303230910.

41. Attman PO, Samuelsson O, Alaupovic P. Lipoprotein metabolism and renal failure. Am J Kidney Dis. 1993;21(6):573592. doi:10.1016/S0272-6386(12)80030-8.

42. Markell MS, Armenti V, Danovitch G, Sumrani N. Hyperlipidemia and glucose intolerance in the post-renal transplant patient. J Am Soc Nephrol. 1994;4(8 Suppl):S37-47.

43. Massy ZA, Kasiske BL. Hyperlipidemia and its management in 
renal disease. Curr Opin Nephrol Hypertens. 1996;5(2):141146. doi:10.1097/00041552-199603000-00007.

44. Mittman N, Avram MM. Dyslipidemia in renal disease. Semin Nephrol. 1996;16(3):202-213.

45. Sutherland WH, Walker RJ, Ball MJ, Stapley SA, Robertson MC. Oxidation of low density lipoproteins from patients with renal failure or renal transplants. Kidney Int. 1995;48(1):227-236. doi:10.1038/ki.1995.288.

46. Ong CS, Pollock CA, Caterson RJ, Mahony JF, Waugh DA, Ibels LS. Hyperlipidemia in renal transplant recipients: natural history and response to treatment. Medicine (Baltimore). 1994;73(4):215-223. doi:10.1097/00005792-19940700000004.

47. Bagdade J, Casaretto A, Albers J. Effects of chronic uremia, hemodialysis, and renal transplantation on plasma lipids and lipoproteins in man. J Lab Clin Med. 1976;87(1):38-48. doi:10.5555/uri:pii:0022214376903280.

48. First MR. Long-term Complications After Transplantation. Am J Kidney Dis. 1993;22(3):477-486. doi:10.1016/S02726386(12)70156-7.

49. Vathsala A, Weinberg RB, Schoenberg L, et al. Lipid abnormalities in cyclosporine-prednisone-treated renal transplant recipients. Transplantation. 1989;48(1):37-43. doi:10.1097/00007890-198907000-00009.

50. Hill MN, Grossman RA, Feldman HI, Hurwitz S, Dafoe DC. Changes in causes of death after renal transplantation, 1966 to 1987. Am J Kidney Dis. 1991;17(5):512-518. doi:10.1016/ S0272-6386(12)80491-4.

51. Braun WE, Marwick TH. Coronary artery disease in renal transplant recipients. Cleve Clin J Med. 1994;61(5):370-385. doi:10.3949/ccjm.61.5.370.

52. Summary of the second report of the National Cholesterol Education Program (NCEP) Expert Panel on detection, evaluation, and treatment of high blood cholesterol in adults (Adult Treatment Panel II). JAMA. 1993;269(23):3015-3023. doi:10.1001/jama.1993.03500230097036.

53. Rosenbaum R, Hoffsten PE, Cryer P, Klahr S. Hyperkalemia after renal transplantation. Occurrence in a patient with insulindependent diabetes. Arch Intern Med. 1978;138(8):12701272. doi:10.1001/archinte.1978.03630330070020.

54. Kaplan B, Wang Z, Abecassis MM, Fryer JP, Stuart FP, Kaufman DB. Frequency of hyperkalemia in recipients of simultaneous pancreas and kidney transplants with bladder drainage. Transplantation. 1996;62(8):1174-1175. doi:10.1097/00007890-199610270-00025.

55. Higgins R, Ramaiyan K, Dasgupta T, et al. Hyponatraemia and hyperkalaemia are more frequent in renal transplant recipients treated with tacrolimus than with cyclosporin. Further evidence for differences between cyclosporin and tacrolimus nephrotoxicities. Nephrol Dial Transplant. 2004;19(2):444450. doi:10.1093/ndt/gfg515. 